\title{
Avaliação dos impactos socioambientais provocados por alagamentos e inundações no bairro Montese, localizado na Bacia do Tucunduba, Belém/PA
}

O crescimento e a consolidação da urbanização das bacias urbanas de Belém explicitaram um panorama ambiental alarmante. O grande adensamento ocasionou mudanças nos processos do ciclo hidrológico por meio da impermeabilização do solo, diminuição da cobertura vegetal e do aterramento das áreas mais baixas. Nessa vertente, o presente trabalho objetivou avaliar as causas e os impactos socioambientais ocasionados por alagamentos e inundações no bairro Montese, localizado no municio de Belém/PA. Optou-se por elaborar mapas de Hipsometria e de declividade como forma de identificar as prováveis áreas suscetiveis a alagamentos no bairro de estudo e entender, através da análise dos resultados, se há uma relação direta entre os mesmos e os alagamentos locais por meio do comportamento altimétrico do local. Com relação à questão dos resíduos sólidos, foi indagado a respeito da frequência com que ocorre a limpeza dos canais próximos de suas residências. A partir da análise dos dados, $65 \%$ afirmaram que a limpeza ocorre de forma anual. Os moradores também foram perguntados sobre as causas dos alagamentos no bairro, onde $28 \%$ alegaram estar relacionada a falta de ações governamentais, sobretudo no que diz respeito a obras de drenagem e saneamento básico. Perguntou-se sobre a existência de ações governamentais voltadas para a melhoria das condições ambientais no bairro, onde 58 \% nunca presenciou alguma ação dos órgãos gestore municipais. Então, observou-se que as causas e impactos decorrem de uma ocupação histórica sem planejamento que não levou em conta as características naturais da bacia. A ausência de políticas públicas relacionadas a falta de estruturas de saneamento, somado a questão dos resíduos sólidos, vem favorecendo a criação de condições de agrave para a ocorrência de alagamentos neste bairro, que juntamente com a ausência de obras de infraestrutura e manutenção dos canais, agravam a problemática em questão, causando inúmeros danos a essa população.

Palavras-chave: Alagamentos; Inundações; Montese; Tucunduba; Impacto Ambiental.

\section{Assessment of socio-environmental impacts caused by floods and inundations in Montese neighborhood, located in the Tucunduba Basin, Belém/PA}

\begin{abstract}
The growth and consolidation of urbanization in the urban basins of Belém made an alarming environmental panorama clear. The great density caused changes in the hydrological cycle processes through the waterproofing of the soil, reduction of the vegetation cover and the grounding of the lower areas. In this regard, the present study aimed to assess the causes and socioenvironmental impacts caused by floods and inundations in the Montese neighborhood, located in the municipality of Belém/PA. It was decided to elaborate hypsometry and slope maps as a way to identify the probable areas susceptible to flooding in the study neighborhood and to understand, through the analysis of the results, if there is a direct relationship between maps as a way to identify the probable areas susceptible to flooding in the study neighborhood and to understand, through the analysis of the results, if there is a direct relationship between
them and the local flooding through behavior. altimetric location. With regard to the issue of solid waste, it was asked about the frequency with which the cleaning of the channels near their them and the local flooding through behavior. altimetric location. With regard to the issue of solid waste, it was asked about the frequency with which the cleaning of the channels near their homes occurs. From the analysis of the data, $65 \%$ stated that cleaning takes place annually. Residents were also asked about the causes of flooding in the neighborhood, where $28 \%$ claimed to be related to a lack of government actions, especially with regard to drainage and basic sanitation works. It was asked about the existence of governmental actions aimed at improving environmental conditions in the neighborhood, where $58 \%$ never witnessed any action by municipal management bodies. Then, it was observed that the causes and impacts stem from a historical occupation without planning that did not take into account the natural characteristics of the basin. The absence of public policies related to the lack of sanitation structures, adde to the issue of solid waste, has favored the creation of aggravating conditions for the occurrence of flooding in this neighborhood, which together with the absence and maintenance of the channels, aggravate the problem in question, causing countless damages to this population.
\end{abstract}

Keywords: Floods; Inundations; Montese; Tucunduba; Environmental Impact.

Topic: Engenharia de Recursos Hídricos

Reviewed anonymously in the process of blind peer.

Sarah Dias Azevedo (ib)

Universidade Federal Rural da Amazônia, Brasil

http://lattes.cnpq.br/7721203184014688

http://orcid.org/0000-0002-5105-1794

saaahazevedo@gmail.com

Cézar Di Paula da Silva Pinheiro (iD

Instituto Tecnológico Vale, Brasil

http://lattes.cnpq.br/9477837707374728

http://orcid.org/0000-0003-3946-2379

cezarpinheiroo@hotmail.com

Paulo Rick Soares Rodrigues (it)

Universidade Federal Rural da Amazônia, Brasil

http://lattes.cnpq.br/4163157291878644

http://orcid.org/0000-0003-2016-6537

rickpaulo83@gmail.com

10.6008/CBPC2237-9290.2020.003.0005
Received: 10/07/2020

Approved: 22/10/2020
Leandro Marques Torres (ii)

Universidade Federal Rural da Amazônia, Brasi

http://lattes.cnpq.br/2678860527695504

http://orcid.org/0000-0001-5976-6340

leandrotorres15@yahoo.com.br

Débora Prissila Reis Sandim (10)

Universidade Federal do Pará, Brasil

http://lattes.cnpq.br/4062780875449217

http://orcid.org/0000-0002-7391-1249

deborasandim@gmail.com
Referencing this:

AZEVEDO, S. D.; PINHEIRO, C. D. P. S.; RODRIGUES, P. R. S.; TORRES, L. M.; SANDIM, D. P. R.. Avaliação dos impactos socioambientais provocados por alagamentos e inundações no bairro Montese, localizado na Bacia do Tucunduba, Belém/PA. Natural Resources, v.10, n.3, p.38-50, 2020. DOI: http://doi.org/10.6008/CBPC22379290.2020.003.0005 


\section{INTRODUÇÃO}

A ocupação de áreas de risco no país, decorre de um processo irregular de urbanização, associado a carência de habitações e da ausência ou ineficiência na aplicação de uma política de habitação e de desenvolvimento, tornado a população que vive nessas áreas altamente suscetível à eventos como enchentes e inundações (FARIAS, 2019). A falta de um Plano Diretor Urbano nas cidades pode ser indicada como uma das causas da ocupação das áreas urbanas impróprias, visto que, é por meio deste que ocorre o planejamento do uso dos solos de várzeas. Contudo, as leis e normas vigentes, que deveriam regulamentar o uso do solo nas margens ou nas nascentes fluviais, não vêm sendo aplicadas de forma afetiva no ordenamento territorial dos municípios (LISBÔA, 2013).

Verifica-se que na região Amazônica, grande parte das margens dos rios urbanos estão sendo habitados, o que associado aos altos índices de precipitações do período de dezembro a maio, conhecido como estação chuvosa, acarretam inundações frequentes, além disso, a junção destes fatores a ausência de infraestrutura, vem causando perdas e danos à população ocupante destas áreas (MARCELINO, 2008). A realidade do município de Belém não foge a esse cenário, a escassez de políticas públicas que buscam incluir as camadas menos abastadas da população e a ocupação desordenada da capital paraense foram pontos cruciais na composição do cenário atual de degradação ambiental dos recursos hídricos da cidade. Tal processo ocasionou graves problemas socioambientais sofridos, atualmente, por considerável parcela da população da cidade (MARINHO et al., 2015). De fato, a urbanização desordenada pode acarretar uma série de problemas, destacando-se alguns como o crescimento da geração de resíduos sólidos, a impermeabilização do solo e a degradação da qualidade da água (COSTA et al., 2015).

A ocupação da área onde fica localizado o bairro do Montese ocorreu a partir dos fluxos migratórios para Belém ocorridos principalmente no século XX, que incidiram em um esgotamento de áreas propicias a habitação na região central da capital paraense (TRINDADE JUNIOR, 2016). Para solucionar tal problemática, áreas próximas aos corpos hídricos, como o Rio Tucunduba passaram a ser ocupadas (FERREIRA, 1995). Este tipo de ocupação em massa e sem planejamento ocasionou uma série de problemas sociais e ambientais para a população que reside nesses locais.

O crescimento e a consolidação da urbanização das bacias urbanas de Belém explicitaram um panorama ambiental alarmante em particular na época mais chuvosa do ano, momento em que os processos de alagamento e inundação promovem uma série de problemas para as populações que moram nessas áreas, tal qual engarrafamentos e obstrução do trânsito da cidade, inundações e outros (PONTES et al., 2017). O grande adensamento ocasionou mudanças nos processos do ciclo hidrológico por meio da impermeabilização do solo, diminuição da cobertura vegetal e do aterramento das áreas mais baixas. Esse processo diminuiu a infiltração e a evapotranspiração, aumentou significativamente o escoamento superficial tendo como grande consequência as cheias e inundações na região da bacia, que afetam diretamente a qualidade de vida dos moradores daquela área (MARINHO et al., 2015).

Nessa vertente, o presente trabalho objetivo avaliar as causas e os impactos socioambientais 
Avaliação dos impactos socioambientais provocados por alagamentos e inundações no bairro Montese, localizado na Bacia do Tucunduba, Belém/PA

AZEVEDO, S. D.; PINHEIRO, C. D. P. S.; RODRIGUES, P. R. S.; TORRES, L. M.; SANDIM, D. P. R.

ocasionados por alagamentos e inundações no bairro Montese, localizado no municio de Belém/PA. Esperase que o estudo tenha capacidade de fornecer maiores informações de interesse público e governamental, em virtude das mazelas sociais encontradas durante a pesquisa, sendo estímulo a criação de melhores políticas públicas e conscientização social da comunidade in loco.

\section{REVISÃO TEÓRICA}

A bacia hidrográfica é entendida como o elemento primário na análise no ciclo hidrológico, sobretudo em sua fase terrestre, que compreende a infiltração e o escoamento superficial (ARAÚJO et al., 2009). Ela compõe uma unidade hidrológica natural, que drena a água de chuvas por canais e tributários para um curso principal, com vazão efluente e deságue diretamente em outro rio (PONTES et al., 2017). Dentro da bacia hidrográfica, os processos de enchentes e as inundações são fenômenos naturais de caráter hidrometeorológico ou hidrológico (LISBÔA, 2013), que se constituem por uma alta vazão em um corpo d'água. As inundações ocorrem quando há o aumento do nível dos rios além da sua vazão normal, ocasionando o transbordamento de suas águas sobre as áreas próximas a ele, quando não corre o trasbordo tem-se somente a cheia natural do corpo d'agua (TUCCl, 2008).

Os períodos de enchentes são comuns nos rios localizados na Amazônia, nesses eventos a água do leito transborda, tomando áreas marginais e acaba por inundá-las em variados níveis de intensidade. Tais áreas marginais são denominadas várzeas, sendo estas um fenômeno natural que recebe influência de fatores hidrográficos, climáticos, edáficos e florísticos. Em rios, as várzeas são mais extensas em seus cursos médio e baixo, local em que a declividade diminui e ocorre o aumento da presença de áreas planas, estas que são mais suscetíveis a ocupação e tem maior incidência de inundações. A ocupação destas áreas em período de baixa vazão dos rios causa prejuízos aos moradores e ao meio ambiente da região (LISBÔA, 2013).

De fato, as inundações constantes nas áreas de várzeas se apresentam como umas das maiores problemáticas enfrentadas pelos moradores dessas áreas. Além dessa questão, os moradores ainda enfrentam problemas de drenagem devido á drenagem natural deficitária e a baixa capacidade de suporte dos solos e a existência do lençol freático (RODRIGUES, 2010). A falta de planejamento nessas áreas produz uma sucessão de danos ambientais, que, por conseguinte, gera uma baixa qualidade de vida para aqueles que lá habitam, acarretando problemas diversos a serem combatidos (CARNEIRO et al., 2010).

A cidade de Belém, capital do Estado do Pará, assim como a maioria das cidades na Amazônia, localiza-se as margens de rios. O município é margeado pelo Rio Guamá e pela Baía do Guajará a uma altitude média de aproximadamente $10 \mathrm{~m}$ acima do nível do mar (SANTOS et al., 2014). Contudo, conforme informações apresentadas no Plano Diretor Urbano (PDU) de Belém, a população da cidade se concentra, principalmente, nos espaços conhecidos usualmente como "baixadas" (FONSECA et al., 2018). Segundo Leão (2014), o termo "baixadas" se refere aos aspectos físicos do relevo, em associação ao local de habitação de população empobrecida e a informalidade, sendo utilizado oficialmente pelo governo na década de 1970 , para denominar ocupações irregulares e carentes, localizadas abaixo da cota altimétrica de $4 \mathrm{~m}$ ou 4,5 m, 
Avaliação dos impactos socioambientais provocados por alagamentos e inundações no bairro Montese, localizado na Bacia do Tucunduba, Belém/PA

AZEVEDO, S. D.; PINHEIRO, C. D. P. S.; RODRIGUES, P. R. S.; TORRES, L. M.; SANDIM, D. P. R.

sujeitas a alagamentos.

Nesse sentido, é importante salientar a diferença entre de enchente, inundação e alagamento. Os alagamentos dizem respeito ao acúmulo de água em áreas longes dos canais, zonas com habitações antrópica, associadas a ausência de sistema de drenagem e baixo coeficiente de escoamento superficial, não se relacionado diretamente com as cheias que ocorrem nos rios (SOUZA, 2004).

A ocupação dessas áreas marginais ao longo do processo histórico de Belém, ocorre devido necessidade de moradias próximas ao centro urbano. O fator localização se sobressaia a falta de estrutura enfrentada pela população. Ocupar áreas pouco valorizadas economicamente e sujeitos a alagamentos e inundações é a saída que essa população tem para ter acesso equipamentos e serviços urbanos, ao trabalho, transporte entre outros (LEÃO, 2014).

Segundo Ponte et al. (2017), a cidade de Belém está situada em ambiente no qual os aspectos geomorfológicos e climáticos acarretam uma condição de eminente risco ambiental a ocorrência de inundações. Os autores ainda afirmam que as áreas de várzea em conjunto a um índice pluviométrico por volta de 3000 mm/ano e as alterações provenientes da urbanização (impermeabilização, alteração topográfica, problemas de saneamento básico) beneficiam a acontecimento de alagamentos especialmente em meio ao período mais chuvosa.

A Bacia do Tucunduba corresponde a 22,02\% das áreas de várzeas de Belém, cerca de 1.055 hectares, sendo que cerca de 575 hectares são de áreas de "baixadas", ela fica localizada no Sudeste capital Belém, desaguando no rio Guamá (MACEDO, 2008). O principal contribuinte da bacia é o igarapé Tucunduba, que conta com 3.600 metros de extensão, sendo este e seus afluentes parte da causa de alagamentos das áreas situadas nos bairros que fazem parte dessa bacia. O igarapé Tucunduba nasce na Travessa Angustura, 3579 entre as Avenidas Almirante Barroso e 10 de dezembro (Bairro do Marco) e tem seu exutório na margem direita do Rio Guamá (Bairro do Guamá), em área da Universidade Federal do Pará (MATOS, 2010).

A bacia do Tucunduba desde o século XVIII teve diversos usos de seu espaço, sendo utilizada para diversas atividades, sejam elas públicas ou privadas, tais como: retirada de madeira para fins econômicos e especiarias, agricultura, pesca, fazenda, colheita de frutos, olaria, construção de abrigo e hospital pela Santa Casa de Misericórdia, limpeza de corpos à margem do igarapé, curtume, transporte fluviais de mercadorias e passageiros, construção de hospital, lazer, habitação, construção da Universidade Federal do Pará (UFPA) e outros (MACEDO, 2008). Nesse contexto, Macedo (2008) afirma que o processo de transformação do seu espaço natural sofrido pela bacia do Tucunduba ao longo dos anos contribuiu para uma segregação tanto social, quanto espacial, que levou a um quadro grave de degradada socioambiental.

A evolução da perda das características naturais da bacia do Tucunduba teve seu início no século XVIII, por meio da doação de uma sesmaria ao Sr. Theodoreto Soares e este permitiu a exploração madeira, pedras, argila e outras especiarias. Posteriormente houve o levantamento do Hospital dos Lázaros do Tucunduba o que gerou um considerava desmatamento das áreas verdes da bacia, o que ocasionou a perda de parte da fauna. Em movimento de degradação continua, na década de 1900 ocorreu a construção do, o 
Avaliação dos impactos socioambientais provocados por alagamentos e inundações no bairro Montese, localizado na Bacia do Tucunduba, Belém/PA

AZEVEDO, S. D.; PINHEIRO, C. D. P. S.; RODRIGUES, P. R. S.; TORRES, L. M.; SANDIM, D. P. R.

hospital Domingos Freire, hoje popularmente conhecido como Barros Barreto, que conforme a história, limpava seus os cadáveres no igarapé do Tucunduba, ainda nesse período o curtume Santo Antônio despejava seus resíduos da lavagem e curtição de couro na área, estendendo essa pratica por vários anos. Já na década de 60, a instalação da UFPA reforçou a perda de fauna e flora da região, visto a grande área desmatada para sua construção. O início da ocupação da área no entorno da bacia na década de 1970 por pessoas em busca de moraria, que ocorreu sem o suporte do governo, acentuou a degradação ambiental da bacia, pois, além do desmatamento, o leito do igarapé foi ocupado (MACEDO, 2008).

Os leitos dos Igarapés foram ocupados de forma desordenada, a ocupação se deu por meio da remoção da cobertura vegetal do solo e utilização de estivas de madeira para a construção de palafitas. Após a fixação, a população empregou seixo, piçarra e resíduos sólidos diversos, como resíduos de açaí e de serrarias para estabelecer o aterro de acesso às palafitas. Além disso, os resíduos utilizados nas vias de acesso foram usados também para aterrar a frente das palafitas, ocasionando mudanças da topografia e represamento ou estagnação de água sob as casas. Logo, estivas de madeira deram lugar às ruas aterradas, o que ocasionou a retificação de canais de drenagem, instalação de ruas laterais e a substituição gradativa das palafitas de madeira por casas de alvenaria.

Em decorrência da grande área desmatada nas margens da bacia do Tucunduba, a bacia sofre com a erosão e, por conseguinte com o assoreamento, o que causa a diminuição da profundidade e o poder de contenção do volume d'água carregado por esses igarapés, espraiando-se e colocando a saúde humana em risco quando ocorre o aumento da vazão. $\mathrm{O}$ crescimento do escoamento superficial na bacia do Tucunduba criou uma série de problemas alarmante como alagamentos e enchentes, intensificado pelo processo de retificação de canais que modificou o curso natural dos rios, causando mudanças em suas dinâmicas naturais, assim como, o processo de aterramento que aconteceu no baixo curso da bacia do Tucunduba, no avanço de seu processo de ocupação (SILVA et al., 2017).

\section{MATERIAIS E MÉTODOS}

A pesquisa é um estudo de caso de caráter descritivo quali-quantitivo, realizado no bairro Montese, na cidade de Belém, estado do Pará. O bairro é atravessado, em toda a sua extensão, pelo Igarapé do Tucunduba, e avizinha-se aos seguintes bairros: Guamá, Canudos, Universitário, Curió Utinga e Marco (DIAS et al., 2015).

De acordo com a Lei 7.806, de 30 de julho de 1996, que delimita as áreas que compõem os bairros de Belém, o bairro Montese compreende a área poligonal que se inicia na interseção da Av. Eunice Weaver (Av. Perimetral) com as áreas da UFPA, contornando esse limite até a interseção do igarapé do Tucunduba (Figura 1).

O bairro está localizado em uma área de baixada, na qual abrange a Universidade Federal do Pará. Como a maioria dos bairros periféricos sua ocupação ocorreu de forma desordenada e espontânea, sendo possível observar a irregularidade espacial em vários pontos, escassez de redes de infraestrutura e de 
Avaliação dos impactos socioambientais provocados por alagamentos e inundações no bairro Montese, localizado na Bacia do Tucunduba, Belém/PA

serviços de saneamento básico. Sua população constitui-se moradores paraense do interior do estado (77\%) e imigrantes de outros estados, em especial do Maranhão (23\%) (DIAS et al., 2015).

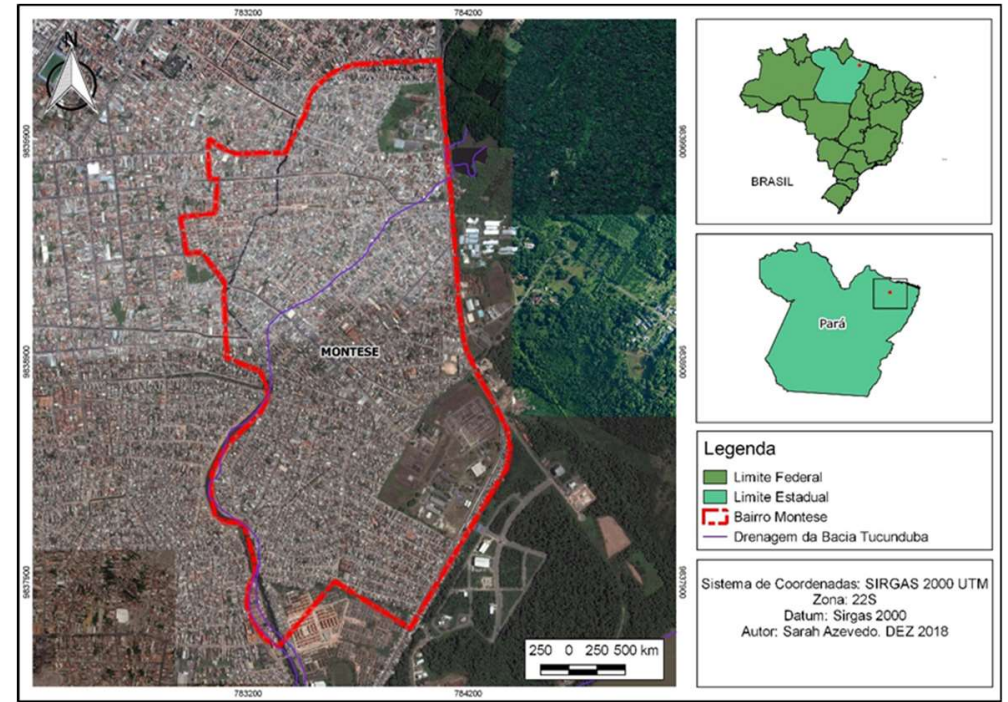

Figura 1: Área de estudo, Bairro Montese.

Desse modo, antes da visita em campo para a coleta de dados, optou-se por elaborar mapas de Hipsometria e de declividade como forma de identificar as prováveis áreas suscetíveis a alagamentos no bairro de estudo e entender, através da análise dos resultados, se há uma relação direta entre os mesmos e os alagamentos locais por meio do comportamento altimétrico do local. Para isso, utilizou-se o programa ArcGIS 10.4 para a produção dos mapas fisiógrafos, onde o primeiro mapa gerado foi de o modelo digital de elevação (MDE) (Figura 2).

Para a caracterização hipsometria da bacia, os dados foram obtidos da plataforma digital da Empresa Brasileira de Agropecuária (Embrapa), em uma escala 1:250.000, a partir de imagem raster, SRTM (Shuttle Radar Topography Mission), em formato GEOTIFF (16 bits), com resolução espacial de 90 metros e sistema de coordenadas geográfica Datum WGS-84.

A constatação das cotas altimétricas, principalmente a hipsometria, permite uma melhor compreensão sobre o escoamento superficial na bacia, pois a água captada por ela percorre o relevo das porções mais altas para as mais baixas ganhando velocidade, direção e, por vezes chegando ao curso d'água, implicando em inundações, desse forma as áreas de menor altitude alinhada com um relevo plano, como observado no bairro do Montese, terá uma maior suscetibilidade a inundação (GONÇALVES et al., 2015).

A declividade é a medida do grau de inclinação de um objeto em relação a um plano horizontal, podendo ser expresso em porcentagem ou em graus. O mapa consiste na representação das diferentes declividades encontradas na área de estudo e foi obtido através da extração das declividades do mesmo arquivo raster utilizado no mapa hipsmoetrico. A declividade foi obtida com curvas de nível de 5 metros, onde primeiramente foi realizado o preenchimento para corrigir possíveis falhas no arquivo vetorial, utilizando a função fill, no diretório do Spatial Analyst Tools (Figura 3). 


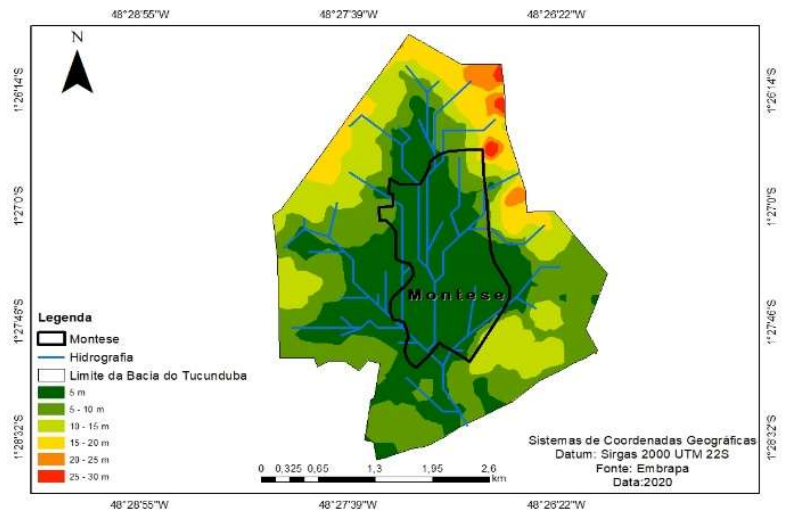

Figura 2: Mapa hipsômetro.

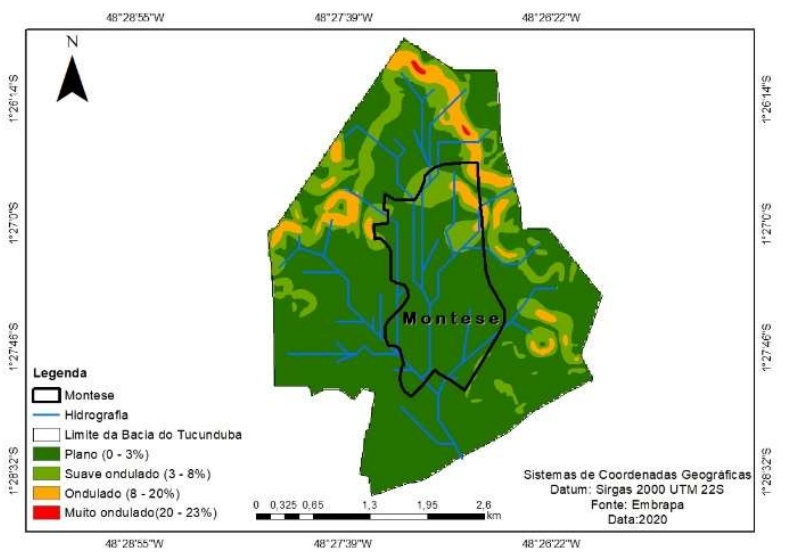

Figura 3: Mapa de declividade.

Para Cristo (2013), os terrenos planos com declividade entre 0 - 3\%, localizados próximos as drenagem, estão sujeitos a ocorrência de inundações periódicas, já os terrenos com declives entre 3\% - 8\% são classificados como suave ondulados, podendo ocorrer processos acumulativos, as áreas entre $8 \%$ - $20 \%$ são tidas como onduladas e o limiar para algumas práticas antrópicas, enquanto que os terrenos que apresentam declividades $>20 \%$ estão sujeitos aos escorregamentos e movimentos de massa.

A etapa de coleta de dados ocorreu de dois modos: (i) visita in situ para traçar quais os pontos mais críticos em relação inundações e alagamentos no bairro, onde foi perguntado de forma informal para os moradores quais ruas apresentavam maiores vulnerabilidade a alagamentos, a partir das respostas foi traçado em quais ruas seriam aplicados os questionários; e posteriormente, utilizou-se como instrumento de coleta de dados o (ii) uso de questionário semiestruturado, com perguntas fechadas, onde procurou-se abordar sobre a percepção dos moradores do bairro no que diz respeito à infraestrutura e saneamento básico, tendo em vista sua influência nos alagamentos locais. Seguindo um roteiro de perfil do entrevistado e posteriormente a construção do cenário do bairro Montese na vivência dos moradores.

Dessa forma, foram aplicados 60 questionários, nos dias 11 e 12 de janeiro de 2019, nas ruas: Celso Malcher, Passagem Lambaris, Rua Orlaria, Vilhena e Rua 2 de Julho. Por meio de registro fotográfico foram identificados alguns interferentes do saneamento básico, que poderiam contribuir para o agravante na localidade além da coleta de modo informal dos relatos dos moradores. Posteriormente os dados foram tabulados e analisados através do programa Excel 2016.

\section{RESULTADOS E DISCUSSÃO}

Inicialmente, se fez necessário caracterizar o grupo pesquisado, tendo em vista que, certos aspectos podem ser correlacionados à percepção apresentada pelas pessoas. Nesse sentido, com relação ao gênero dos entrevistados observou-se predominância do gênero masculino, 58\% dos entrevistados. Na distribuição por faixa etária, identificou-se a predominância de idades acima de 40 anos com 55\% (Figura 4), revelando a composição dos entrevistados de grande maioria adulta.

Quanto à escolaridade (Figura 5), a maioria dos entrevistados (60\%) possuía apenas o ensino médio, seguidos pelos que possuíam somente o ensino fundamental (40\%). Nenhum dos entrevistados possuía nível 
superior.

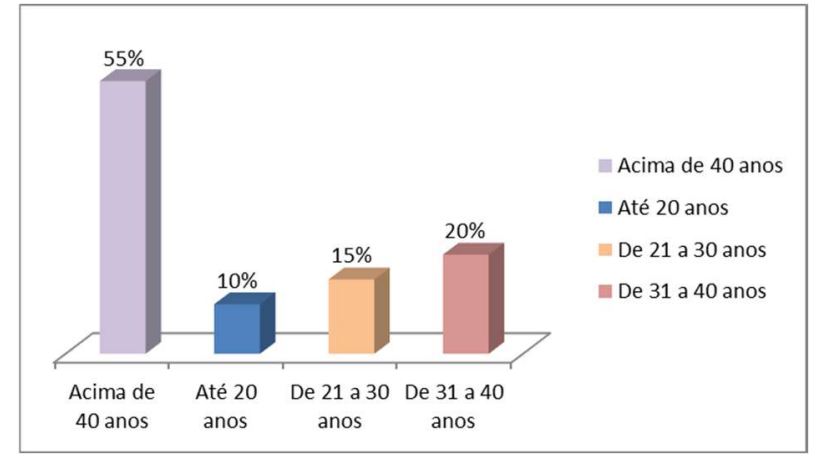

Figura 4: Distribuição da população quanto à faixa etária.

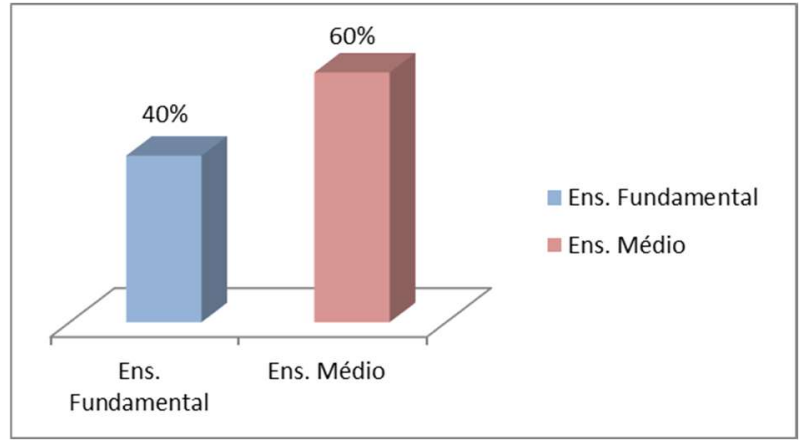

Figura 5: Grau de escolaridade dos entrevistados.

Procurou-se também investigar a respeito do tempo de moradia dos entrevistados, haja vista que, esse aspecto encontra-se intimamente relacionado com o grau de conhecimento que o indivíduo apresenta sobre a realidade vivida. A partir das respostas, optou-se por estabelecer intervalos de tempo (Figura 6), juntamente com as informações obtidas.

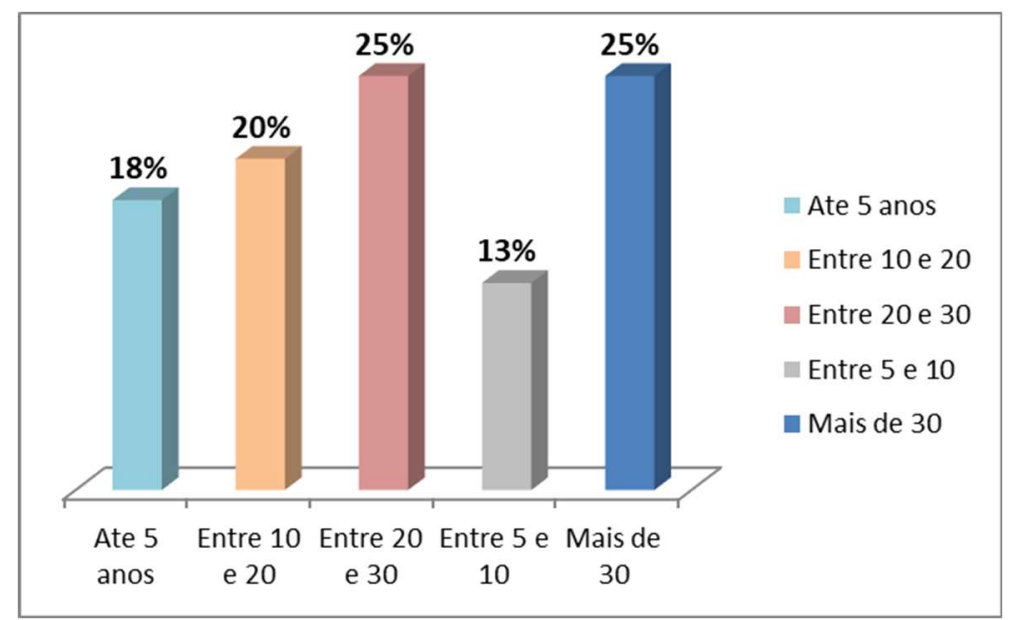

Figura 6: Tempo de residência dos entrevistados no local pesquisado.

Observou-se que as opções referentes a idades entre 20 e 30 anos e com mais de 30 anos obtiveram cada uma $25 \%$ das respostas registradas, seguidos por $20 \%$ entre 10 e 20 anos, $28 \%$ até 5 anos e $13 \%$ entre 5 e 10 anos. Nesse sentido, as pessoas que vivem em uma determinada região há um longo tempo tendem ter um melhor entendimento da realidade da região, como os riscos ambientais nela existentes. Dessa forma, o tempo vivido torna-se de grande importância estando diretamente ligados as sensações, sentimentos e emoções em relação ao lugar habitado.

Quando indagados sobre a frequência em que ocorrem alagamentos próximos de suas residências, $80 \%$ dos entrevistados afirmaram acontecer sempre que chove. Além disso, $78 \%$ afirmaram ter algum tipo de contato com a água oriunda dessa precipitação, devido, sobretudo, a falta de infraestrutura e saneamento básico no local, assim, foi realizada uma visita ao local de estudo após um evento de precipitação, para que se pudessem realizar registros referentes ao grau de alagamento do local (Figura 7).

Assim, observou-se que o bairro da Montese possui graves problemas relacionados à drenagem local, 
acarretando intensos alagamentos. Tal problemática decorre de uma urbanização desordenada e sem qualquer planejamento no que diz respeito a presença de infraestrutura necessária para a drenagem urbana (TUCCl, 2008), sendo uma realidade de diversos centros urbanos brasileiros. Além disso, para Pereira et al. (2017), juntamente com a urbanização ocorre o crescimento de áreas impermeáveis que contribuem para a diminuição de locais de escoamento e infiltração da água proveniente de precipitações.

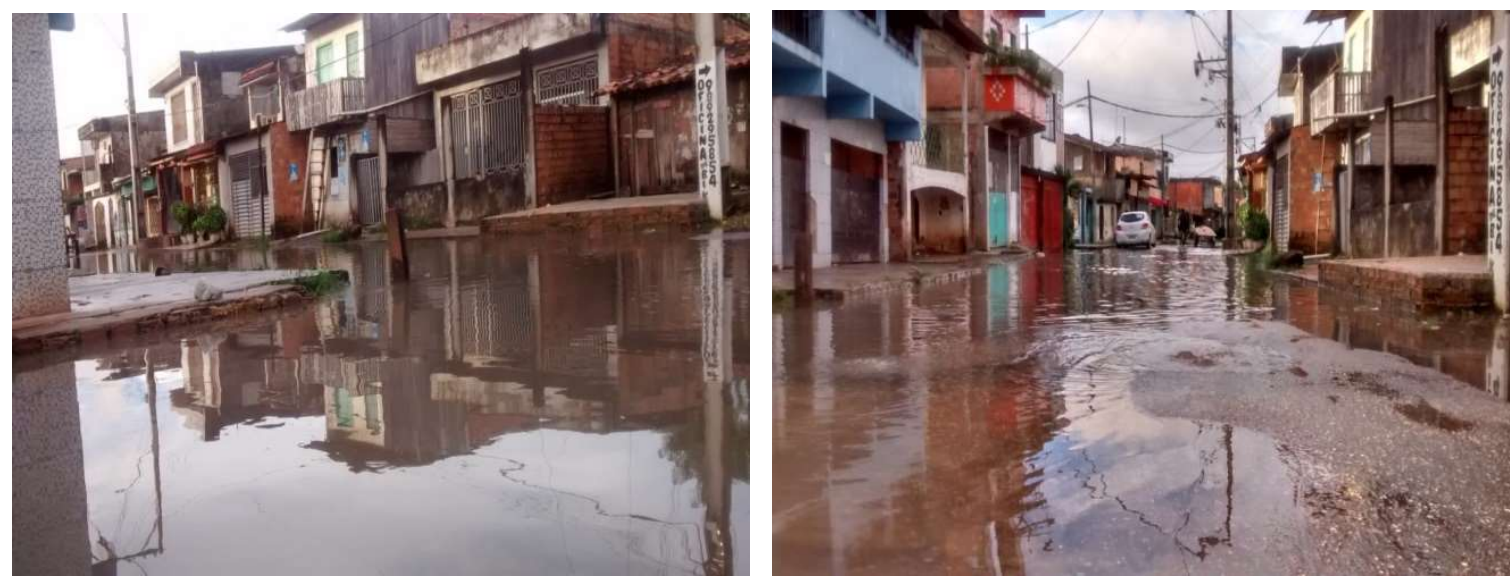

Figura 7: Alagamentos no bairro da Montese após evento de precipitação.

Ademais, também se observou a falta de estruturas de saneamento, além da questão da disposição irregular de resíduos sólidos que colaboram para agravar os alagamentos neste bairro. Sobre o assunto, de acordo com Costa et al. (2015) e Pinheiro (2018), na região metropolitana de Belém (RMB) ocorre um quadro alarmante em relação aos resíduos sólidos, visto que apesar da existência de serviços de limpeza urbana e varrição, esses não têm capacidade para coletar todos os resíduos gerados, sobretudo nas áreas periféricas. De modo que, consequentemente ocorre o despejo de resíduos em terrenos abandonados e em algumas ocasiões em locais próximos aos cursos d'água ou mesmo diretamente nos canais.

Dando continuidade, com relação à questão dos resíduos sólidos, foi indagado aos entrevistados sobre a frequência com que ocorre a limpeza dos canais próximos de suas residências. A partir da análise dos dados, $65 \%$ afirmaram que a limpeza ocorre de forma anual, enquanto $20 \%$ alegaram que a mesma acontece somente após uma grande quantidade de chuva, 10\% mensalmente e 5\% semanalmente (Figura 8 ).

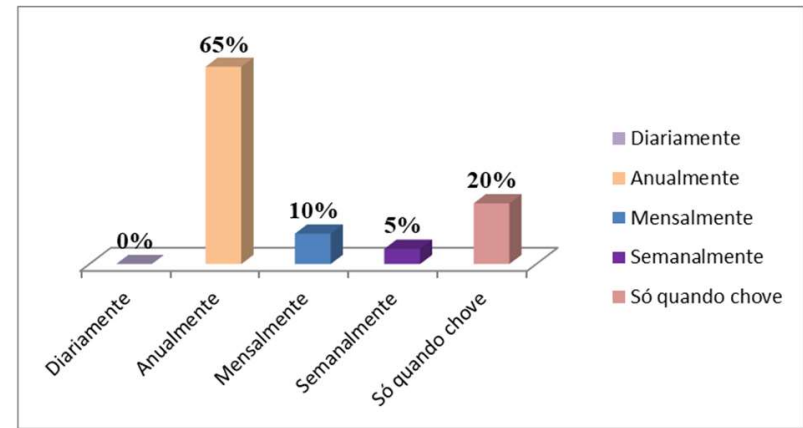

Figura 8: Frequência com que os ocorre à limpeza dos canais próximos à residência dos entrevistados.

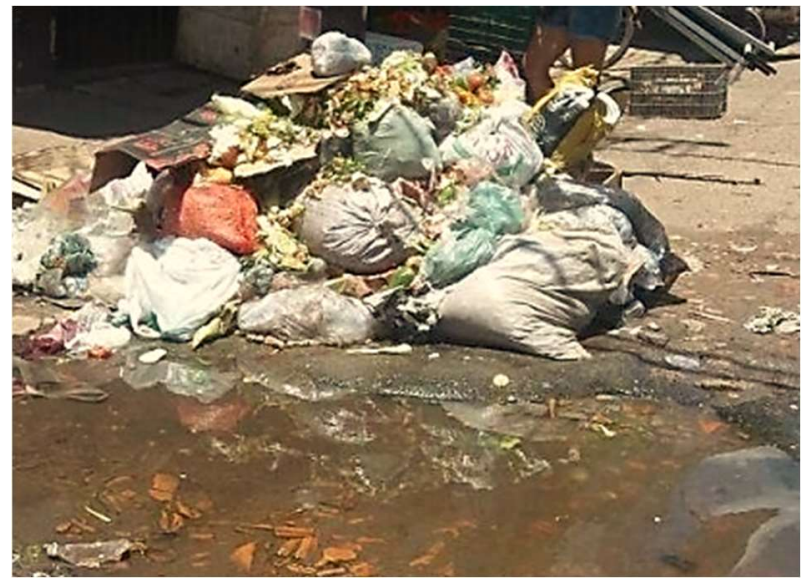

Figura 9: Disposição irregular de resíduos no bairro Montese. 
Dessa forma, percebe-se a falta de atuação da prefeitura com relação à limpeza contínua dos canais no bairro estudado. Essa problemática também é relatada por Souza et al. (2019), em seu estudo sobre o sistema de drenagem urbana e resíduos sólidos do bairro Curió Utinga-Belém/PA. Assim, verifica-se que o trabalho da prefeitura, no que diz respeito a realização de dragagem, retirada de entulho e desobstrução de bueiros é ineficiente, não conseguindo conter os problemas de alagamento, e algumas vezes até agravando a situação. Em seguida foi perguntado se ocorria acúmulo de resíduos sólidos próximas a áreas de residências, onde 55\% alegaram que sim (Figura 9).

Segundo Sadeck et al. (2017), a disposição de resíduos sólidos no solo constitui um meio de exposição humana a diversas substâncias tóxicas, assim como pode ser considerado o potencial esgotamento dos serviços ecossistêmicos precisos para a degradação completa do resíduo depositado, assim como o acúmulo gerado ameaça se deslocar para dentro do canal durante o período chuvoso causando a obstrução do mesmo.

Em se tratando da área de estudo, essa questão está diretamente relacionada a falta de educação ambiental por parte da população local, uma vez que, de acordo com 83\% dos entrevistados, a Prefeitura realiza o recolhimento de resíduos na área ao menos três vezes por semana. Um fator a destacar é a presença de carroceiros na área com uso de tração animal ou não, comum em outros bairros de Belém (PINHEIRO, 2018), que, muitas das vezes são solicitados para despejar resíduos de outras ruas em determinados pontos ou nos canais do bairro.

Nesse sentido, segundo Carvalho et al. (2017), a educação ambiental é uma ferramenta de mitigação de degradação ambiental, tendo a função transformadora no qual a corresponsabilização do indivíduo é essencial para a proteção ambiental e da saúde humana, sendo assim, uma ferramenta de grande importância para o despertar da sensibilização ambiental nos indivíduos. Posteriormente foi perguntado aos moradores sobre a ocorrência de doenças relacionadas a veiculação hídrica nos mesmos, onde os resultados podem ser observados a seguir (Figura 10).

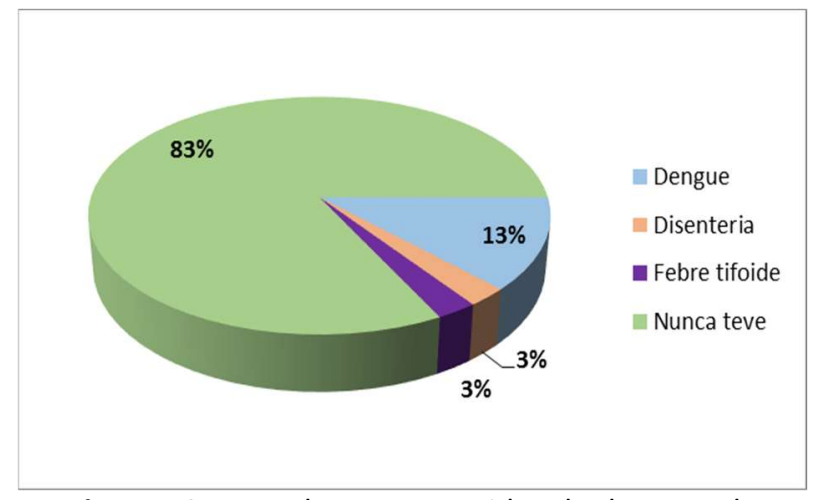

Figura 10: Moradores acometidos de doenças de veiculação hídrica.

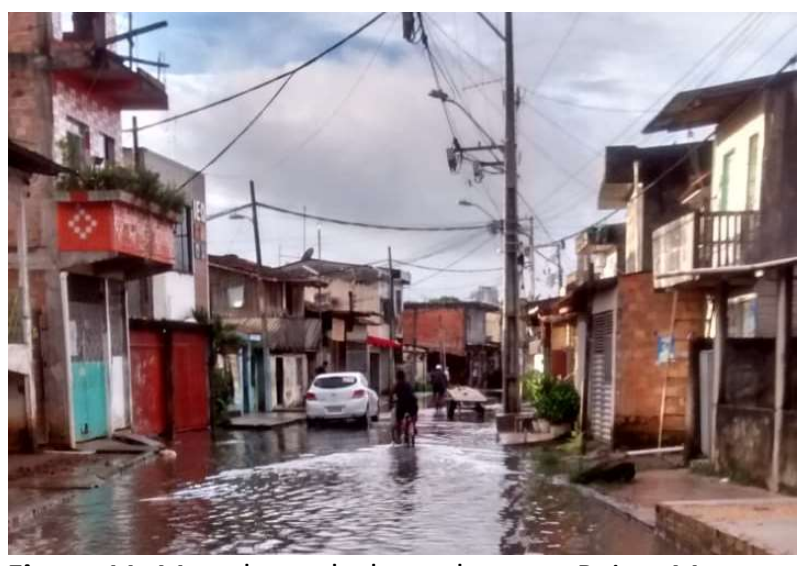

Figura 11: Moradores deslocando-se no Bairro Montese após 2 horas de chuva.

Também foi comentado pelos entrevistados a respeito do recorrente número de casos de diarreia ou amebíase em crianças da comunidade local, que também podem estar relacionados a questão das 
enchentes, uma vez que há o contato direto dos moradores com a água do local (Figura 11).

Posteriormente foi perguntado se os eventos de alagamento costumam inundar as residências dos entrevistados, onde $48 \%$ responderam positivamente. Além disso, perguntou-se sobre o nível que a água chega nesses eventos, com a grande maioria, cerca de $68 \%$, afirmando chegar na altura da canela. Sendo comum a perda de bens materiais, visto que $63 \%$ dos entrevistados relatam o dano da perda de eletrodomésticos e móveis.

Os moradores também foram perguntados sobre as causas dos alagamentos, no bairro, onde $28 \%$ alegaram estar relacionada a falta de ações governamentais, sobretudo no que diz respeito a obras de drenagem e saneamento básico (Figura 12).

De acordo com Cristo et al. (2014), as características da bacia constituinte do bairro Montese, somado aos problemas de saneamento básico locais, é um fator decisório na abrangência dos alagamentos. Uma vez que na Bacia do Tucunduba ocorre significativa predominância de áreas de planície no terreno da bacia, conforme evidenciado nas Figuras 2 e 3, onde cerca de 44,30\% da área total da bacia, ou seja, quase metade da área é constituída por uma ampla planície de inundação, abaixo da cota de $4 \mathrm{~m}$. Onde estima-se que, $73,50 \%$ da Bacia do Tuncuduba seja ocupada, o que interfere diretamente nas características morfológicas e hidrológicas da bacia, aumentando o escoamento superficial e ainda a retificação dos canais, que somado a outros fatores alteram a dinâmica natural da bacia ocasionado alagamentos e enchentes.

Por fim, perguntou-se sobre a existência de ações governamentais voltadas para a melhoria das condições ambientais no bairro, onde 58 \% nunca presenciou alguma ação dos órgãos gestores municipais, $30 \%$ notam a ausência do governo, 10\% presenciou algumas obras locais, mas identificam a demora na conclusão das mesmas e 3 \% recebeu alguma orientação com relação a educação ambiental por vias de programas (Figura 13).

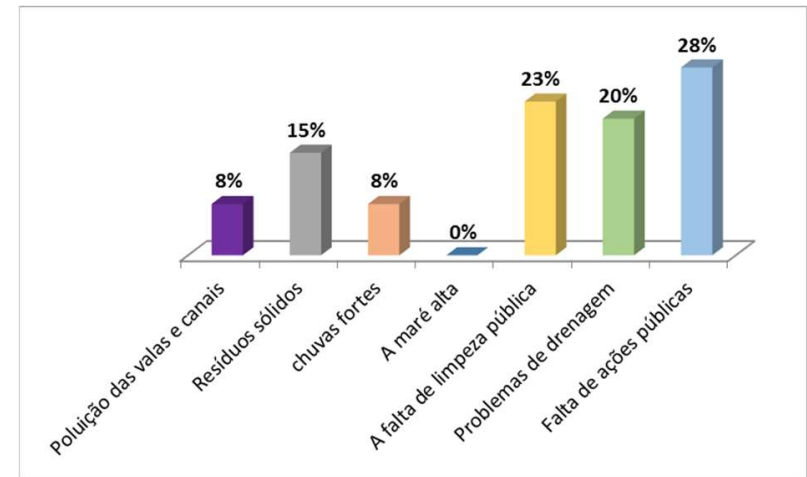

Figura 12: Percepção dos moradores referente a causa dos alagamentos locais.

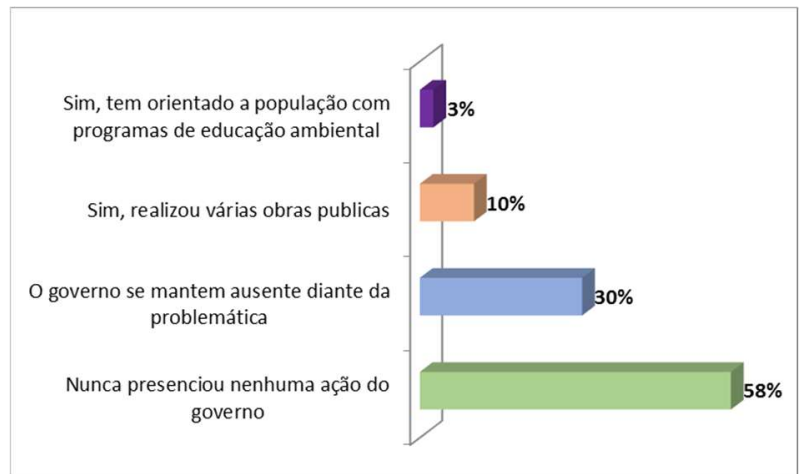

Figura 13: Ações governamentais para melhoria ambiental no Bairro Montese.

O resultado exposto colabora para evidenciar a falta de uma presença mais ativa do poder público no bairro, colaborando para a sensação de abandono e descaso relatada pelos moradores locais. Tornando explicito a necessidade de maiores ações no bairro, voltadas para a melhoria da qualidade de vida e bemestar da comunidade como um todo. 
Avaliação dos impactos socioambientais provocados por alagamentos e inundações no bairro Montese, localizado na Bacia do Tucunduba, Belém/PA

AZEVEDO, S. D.; PINHEIRO, C. D. P. S.; RODRIGUES, P. R. S.; TORRES, L. M.; SANDIM, D. P. R.

\section{CONCLUSÕES}

Os moradores do bairro Montese se encontram em uma situação de grande vulnerabilidade ambiental. O fato decorre de uma ocupação histórica sem planejamento que não levou em conta as características naturais da bacia. A ausência de políticas públicas relacionadas a falta de estruturas de saneamento, somado a questão dos resíduos sólidos, vem favorecendo a criação de condições de agrave para a ocorrência de alagamentos neste bairro, que juntamente com a ausência de obras de infraestrutura e manutenção dos canais, agravam a problemática em questão, causando inúmeros danos a essa população.

Nesse sentido, há a necessidade de uma maior participação do poder público através de obras de infraestrutura e oferecimento de projetos voltados à educação ambiental para que a população entenda também sua responsabilidade na manutenção da qualidade socioambiental da área.

\section{REFERÊNCIAS}

ARAÚJO, L. E.; SOUSA, F. A. S.; MORAES NETO, J. M.; SOUTO, J. S.; REINALDO, L. R. L. R.. Bacias hidrográficas e impactos ambientais. Qualitas Revista Eletrônica, v.8, n.1, p.1-18, 2009. DOI: http://dx.doi.org/10.18391/qualitas.v8i1.399

CARNEIRO, P. R. F.; CARDOSO, A. L.; ZAMPRONIO, G. B.; MARTINGIL, M. C.. A gestão integrada de recursos hídricos e do uso do solo em bacias urbano-metropolitanas: o controle de inundações na bacia dos Rios Iguaçu/Sarapuí, na Baixada Fluminense. Ambiente \& Sociedade, v.13, n.1, p.29-49, 2010. DOI: https://doi.org/10.1590/S1414753X2010000100003.

CARVALHO, A. B.; HERRERA, J. A.. Contribuições da educação ambiental para mitigação dos efeitos de eventos climáticos extremos na bacia hidrográfica do igarapé altamira em Altamira-PA. Geografia Ensino \& Pesquisa, v.21, n.3, p.196203, 2017. DOI: http://doi.org/10.5902/2236499425822

COSTA, C.; BITTENCOURT, G.; TEIXEIRA, L.; BLANCO, C.. Problemática dos resíduos sólidos no sistema de drenagem urbana de Belém/PA. Revista Gestão \& Sustentabilidade Ambiental, v.4, n.2, p.329-344, 2015. DOI: http://dx.doi.org/10.19177/rgsa.v4e22015329-344

CRISTO, S. S. V.. Abordagem geográfica e análise do patrimônio geomorfológico em unidade de conservação da natureza: aplicação na Estação Ecológica Serra Geral do Tocantins e área de entorno, estados do Tocantins e Bahia. Tese (Doutorado) - Universidade Federal do Rio Grande do Sul, Porto Alegre, 2013. DOI:

http://dx.doi.org/10.19177/rgsa.v4e22015329-344

CRISTO, L. A.; LUZ, L. M.. Morfologia e Uso do Solo na Bacia Urbana do Tucunduba, Belém/PA. Revista Brasileira de Geografia Física, v.7, n.03, p.466-475, 2014. DOI: https://doi.org/10.26848/rbgf.v7.3.p466-475

DIAS, M. L.; COSTA, C. H. G.; SANTOS, J. I. N.; FERREIRA, M. R. S.; SILVA, N. R. S.. Terra Firme: uma reflexão sobre o atual processo de regularização fundiária. Revista Universo \& Extensão, v.3, n.3, 2015.
FARIAS, A. S.. Inundações urbanas em Francisco Beltrão/PR: riscos e vulnerabilidades socioambientais. Tese (Doutorado) - Universidade Federal do Paraná, Curitiba, 2019

FERREIRA, C. F.. Produção do espaço urbano e degradação ambiental: um estudo de caso sobre a várzea do Igarapé do Tucunduba Belém-Pará. Dissertação (Mestrado) Universidade de São Paulo, São Paulo, 1995.

FONSECA, A.; GUEDES, J.; SILVA, M.; SILVA, L.. Mapeamento das áreas sujeitas a inundações no distrito administrativo d'água, município de Belém, por meio de técnicas de geoprocessamento. In: CONGRESSO DE CADASTRO MULTIFINALITÁRIO E GESTÃO TERRITORIAL, 13. Anais. Florianópolis: COBRAC, 2018.

GONÇALVES, E. D.; SANTOS, M. D. L. S.; SOARES, J. A. C.; SOUZA, P. H. N.; MOURÃO, F. V.; CASTRO, K. F.; SOUSA, A. C. S. R.. Aplicação do Sistema de Informação Geográfica na Microbacia dos Lagos Bolonha e Água Preta (PA). Boletim Técnico Científico do CEPNOR, v.15, n.1, p.43-50, 2016. DOI: http://dx.doi.org/10.32519/tjfas.v15i1.2129

LEÃO, M. B. M. S.. Macrodrenagem e urbanização na Bacia da Estrada Nova: conflitos entre APP urbana e reassentamentos nas baixadas de Belém/PA. In: SEMINÁRIO NACIONAL SOBRE TRATAMENTO DE APP EM MEIO URBANO E RESTRIÇÕES AMBIENTAIS AO PARCELAMENTO DO SOLO, 3. Anais. Belém: ANPUR, 2014.

LISBÔA, T. F. P.. Vulnerabilidade e capacidade de resposta à ameaça de inundação na Bacia Hidrográfica do Rio Paracuri, Belém/Pa. Dissertação (Mestrado) - Universidade Federal do Pará, Belém, 2013.

MACEDO, C. M.. Meio ambiente na percepção dos moradores das ocupações riacho doce e pantanal na bacia hidrográfica do igarapé Tucunduba/Belém/Pará. Dissertação (Mestrado) - Universidade Federal do Pará, Belém, 2008.

MARCELINO, E.. Desastres Naturais e Geotecnologias: conceitos básicos. Santa Maria: INPE, 2008. 
MARINHO, A. V. R.; SARAIVA, J. S.; RODRIGUES, E. C.. Caracterização socioambiental da bacia urbana do Tucunduba, Belém/PA. Revista do Instituto Histórico e Geográfico do Pará, v.2, n.02, 2016. DOI: http://doi.org/10.17553/2359-0831/ihgp.v2n2p96-107

MATOS, F. C.. Caracterização qualitativa dos impactos ambientais causados pela ocupação urbana no igarapé do Tucunduba. Dissertação (Mestrado) - Universidade de Taubaté, Taubaté, 2010.

PEREIRA, P. P.; ITO, A. H.. Efeitos da urbanização e soluções sustentáveis para o sistema de drenagem. Synergismus Scyentifica, v.12, n.1, p.183-195, 2017.

PINHEIRO, C. P. S.. Diagnósticos e proposições sobre a questão dos resíduos sólidos no conjunto Catalina, bairro do Mangueirão, Belém/PA. Educação Ambiental em Ação, v.64, p.1, 2018.

PONTES, M. L. C.; LIMA, A. M.; SILVA JUNIOR, J. A. S.; SADECK, C. C. A.. Dinâmica das áreas de várzea do município de Belém/PA e a influência da precipitação pluviométrica na formação de pontos alagamentos. Caderno de Geografia, v.27, n.49, p.285-303, 2017.

DOI: https://doi.org/10.5752/p.2318-2962.2017v27n49p285

SANTOS, F. A. A., ROCHA, E. J. P.. Alagamento e inundação em áreas urbanas. Estudo de caso: cidade de Belém. Revista GeoAmazônia, v.1, n.02, p.33-55, 2014. DOI: http://doi.org/10.17551/2358-1778/geoamazonia.n1v2p33$\underline{55}$

SILVA, S. A.; GAMA, J. A.S.; CALADO, H. N.; SOUZA, B..

Saneamento básico e saúde pública na bacia hidrográfica do Riacho Reginaldo em Maceió, Alagoas. Engenharia Sanitária e Ambiental, v.22, n.4, p.699-709, 2017. DOI: http://doi.org/10.1590/S1413-41522017146971

SOUZA, C.. Risco a inundações, enchentes e alagamentos em regiões costeiras. In: SIMPÓSIO BRASILEIRO DE DESASTRES NATURAIS, 1. Anais. Florianópolis: Instituto geológico, 2004. p.231-247.

SOUZA, L. D. P.; TORRES, E. E. S. A.; XAVIER, B. V. M. P.; SOUTO, C. K. B.; BARROS, K. C.; TELES, A. I. L.; PRATA, L. K. F.; DIAS, E. C.; ANDRADE, A. A.; GOMES, N. C. R.; BITTENCOURT, G. M.; FERNANDES, L. L.. Abordagem da atual situação do sistema de drenagem urbana e resíduos sólidos do bairro Curió Utinga-Belém/PA. Brazilian Journal of Development, v.5, n.8, p.13397-13407, 2019.

DOI: https://doi.org/10.34117/bjdv5n8-141

TRINDADE JUNIOR, S.-C. C.. Formação metropolitana de Belém (1960-1997). Belém: Paka-Tatu, 2016.

TUCCI, C. E. M.. Águas urbanas: Desenvolvimento urbano. Estudos avançados, v.22, n.63, p.97-112, 2008. DOI: https://doi.org/10.1590/S0103-40142008000200007

A CBPC - Companhia Brasileira de Produção Científica (CNPJ: 11.221.422/0001-03) detém os direitos materiais desta publicação. Os direitos referem-se à publicação do trabalho em qualquer parte do mundo, incluindo os direitos às renovações, expansões e disseminações da contribuição, bem como outros direitos subsidiários. Todos os trabalhos publicados eletronicamente poderão posteriormente ser publicados em coletâneas impressas sob coordenação da Sustenere Publishing, da Companhia Brasileira de Produção Científica e seus parceiros autorizados. Os (as) autores (as) preservam os direitos autorais, mas não têm permissão para a publicação da contribuição em outro meio, impresso ou digital, em português ou em tradução. 